\title{
Expression of dorsal-ventral genes during early development of Rhynchosciara americana embryos
}

\section{J.C. Carvalho, D.N. Rocha, R.V. Bruno, \\ C.E. Vanario-Alonso and E. Abdelhay}

\author{
Laboratório de Biologia Molecular Maury Miranda, \\ Instituto de Biofísica Carlos Chagas Filho, \\ Universidade Federal do Rio de Janeiro, Rio de Janeiro, RJ, Brasil
}

\section{Correspondence \\ E. Abdelhay \\ Laboratório de Biologia Molecular Maury Miranda, IBCCF, CCS \\ Bloco G, Sala G-59 \\ 21949-900 Rio de Janeiro, RJ \\ Brasil \\ Fax: +55-21-2280-8193 \\ E-mail: abdelhay@biof.ufrj.br \\ Presented at the XI Congresso Brasileiro de Biologia Celular, Campinas, SP, Brazil, July 15-18, 2004.}

Research supported by CNPq, CAPES and PRONEX.

Received May 27, 2004 Accepted October 19, 2004

\begin{abstract}
The establishment of dorsal-ventral polarity in Drosophila is a complex process which involves the action of maternal and zygotically expressed genes. Interspecific differences in the expression pattern of some of these genes have been described in other species. Here we present the expression of dorsal-ventral genes during early embryogenesis in the lower dipteran Rhynchosciara americana. The expression of four genes, the ventralizing genes snail (sna) and twist (twi) and the dorsalizing genes decapentaplegic (dpp) and zerknüllt (zen), was investigated by whole-mount in situ hybridization. Sense and antisense mRNA were transcribed in vitro using UTP-digoxigenin and hybridized at $55^{\circ} \mathrm{C}$ with dechorionated fixed embryos. Staining was obtained with anti-digoxigenin alkaline phosphatase-conjugated antibody revealed with NBT-BCIP solution. The results showed that, in general, the spatial-temporal expression of $R$. americana dorsalventral genes is similar to that observed in Drosophila, where twi and $s n a$ are restricted to the ventral region, while $d p p$ and zen are expressed in the dorsal side. The differences encountered were subtle and probably represent a particular aspect of dorsal-ventral axis determination in R. americana. In this lower dipteran sna is expressed slightly later than twi and $d p p$ expression is expanded over the lateral ectoderm during cellular blastoderm stage. These data suggest that the establishment of dorsal-ventral polarity in $R$. americana embryos follows a program similar to that observed in Drosophila melanogaster.
\end{abstract}

Key words

- Rhynchosciara americana

- Lower dipteran

- Axis patterning

- Dorsal-ventral genes

- Early embryogenesis
The establishment of dorsal-ventral polarity in Drosophila embryos is a complex process which involves the action of maternal and zygotically expressed genes. The first step in the establishment of the dorsalventral axis is the migration of the oocyte nuclei to a dorsal anterior position. In this position the nuclei initiate a cascade of interand intracellular signaling that culminates with the localization of dorsal protein exclusively in the ventral nuclei of the embryo (1).

The dorsal gene plays a particularly crucial role in the specification of dorsal-ventral positional identities during early development. The gradient of nuclear dorsal protein functions as a morphogen that directly activates or represses the transcription of tissuespecific genes in the pathway (2). Along the 
ventral midline, where the concentration of nuclear Dorsal protein is the highest, twist (twi) and snail (sna) are activated in the presumptive mesoderm. Dorsally, the activity of Dorsal is so low that it can neither activate twi and sna nor repress decapentaplegic ( $d p p$ ) and zerknüllt (zen), so that only $d p p$ and zen are expressed. The dorsalizing genes $d p p$ and zen are responsible for the differentiation of dorsal ectodermal derivatives, including the amnioserosa and dorsal epidermis (3-6). twi, sna, $z e n$, and dpp are direct targets of Dorsal, and their regulation represents the earliest subdivision of the dorsal-ventral axis into discrete regions of zygotic gene expression.

Homologues of maternal dorsal-ventral system genes have been described only in some dipterans while homologues for zygotic genes of this system were also identified in other species of arthropods and some chordates (7). These findings suggest that dorsal-ventral patterning occurs according to a common genetic control in different organisms. However, interspecific differences in the pattern of dorsal-ventral gene expression exist and have been well documented for insects such as Tribolium and Schistocerca gregaria (8-10).

In the present study, we analyzed the

Figure 1. Phylogenetic tree showing the closeness of the species considered in the present study. Adapted from Rohr et al. (14).

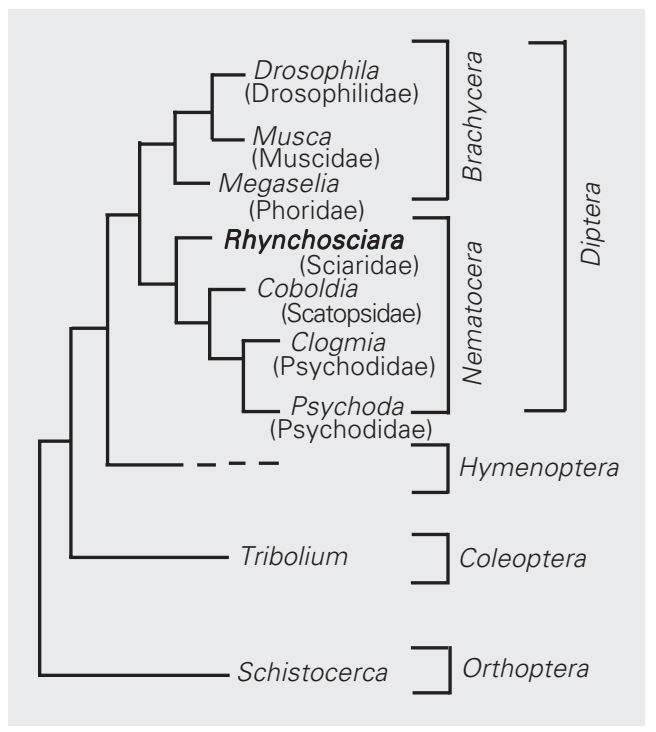

pattern of expression of some zygotic genes of the dorsal-ventral system in the lower dipteran $R$. americana. In this species the pattern of expression of segmentation genes (gap genes) is quite different from those observed in higher dipterans (Carvalho JC, Rocha DN, Vanario-Alonso CE and Abdelhay $\mathrm{E}$, unpublished results). $R$. americana shows important differences in several stages of embryogenesis when compared to Drosophila (11). $R$. americana has a very long development. At $22^{\circ} \mathrm{C}$, embryos hatch after 12 days in comparison to the $24 \mathrm{~h}$ taken by Drosophila embryos and present an unusual developmental pattern, which combines some conserved characteristics similar to early and late Drosophila development with a different mid-stage (11). Rhynchosciara presents an intermediate step between blastoderm formation and gastrulation. After cellularization the blastoderm starts to differentiate into a short embryonary primordium and an extraembryonary membrane (11). This differentiation culminates in a strong spatial cellular polarization which divides the embryo into a vegetative pole - rich in germplasm with few cells - and a germinative pole that contains the embryo primordium, which is very condensed in this species (11). However, interestingly, the data obtained in the present study suggest that the genetic control of the dorsal-ventral axis seems to be remarkably conserved in $R$. americana, with some minor differences probably due to variations in gene regulation.

To analyze these expression patterns, $R$. americana embryos were staged according to Carvalho et al. (11) and whole-mount in situ hybridization was performed as described by Tautz and Pfeifle (12), except that embryo hybridization and washing were performed at $50^{\circ} \mathrm{C}$. Drosophila cDNA probes for the genes under study were obtained from Dr. Stephen Small (New York University) and were used to transcribe sense and antisense RNA probes. We used sense RNA under the same stringency and temperature 
conditions as control and no labeling could be detected. The photographic images were digitized and then edited electronically using Adobe Photoshop software.

We examined the expression of twi, sna, $d p p$, and zen in the early embryogenesis of $R$. americana. For whole-mount in situ hybridization we used anti-sense mRNA probes obtained from $D$. melanogaster cDNAs. Given the phylogenetic closeness of the two species (Figure 1), the use of heterologous probes suited our purpose and we were able to analyze the expression of all four genes.

sna gene expression was detected during a short period of $R$. americana early embryogenesis. This expression was confined to the syncytial blastoderm stage $(8 \mathrm{~h})$ and sna transcripts were localized in the ventral region of the embryo (Figure 2A). Expression of twi mRNA was also detected in the ventral region of the embryo, although at a later time (12-18 h). twi gene expression was detected during blastoderm cellularization of embryo nuclei (Figure 2B). These results contrast with those obtained for Drosophila, in which both the sna and twi genes are initially expressed at the 11th nuclear cleavage (4). In Drosophila, the cellular blastoderm forms during the 14th mitotic cycle and thus sna and $t w i$ are expressed early in the syncytial blastoderm. This temporal difference in $t w i$ expression could be related to the longer embryogenesis of $R$. americana. Probably the temporal regulation of sna and twi expression in $R$. americana is more evident than in Drosophila due to the longer time taken by cellularization $(24 \mathrm{~h}$ in $R$. americana versus $4 \mathrm{~h}$ in $D$. melanogaster).

In Drosophila, Dorsal directly activates sna and twi expression and the width of the sna domain depends on twi. However, the initiation of twi expression is essentially normal in sna mutant embryos and the initiation of sna expression is normal in twi mutant embryos (6). Thus, the temporal difference observed in $R$. americana for sna and twi expression is a particular aspect of this spe-
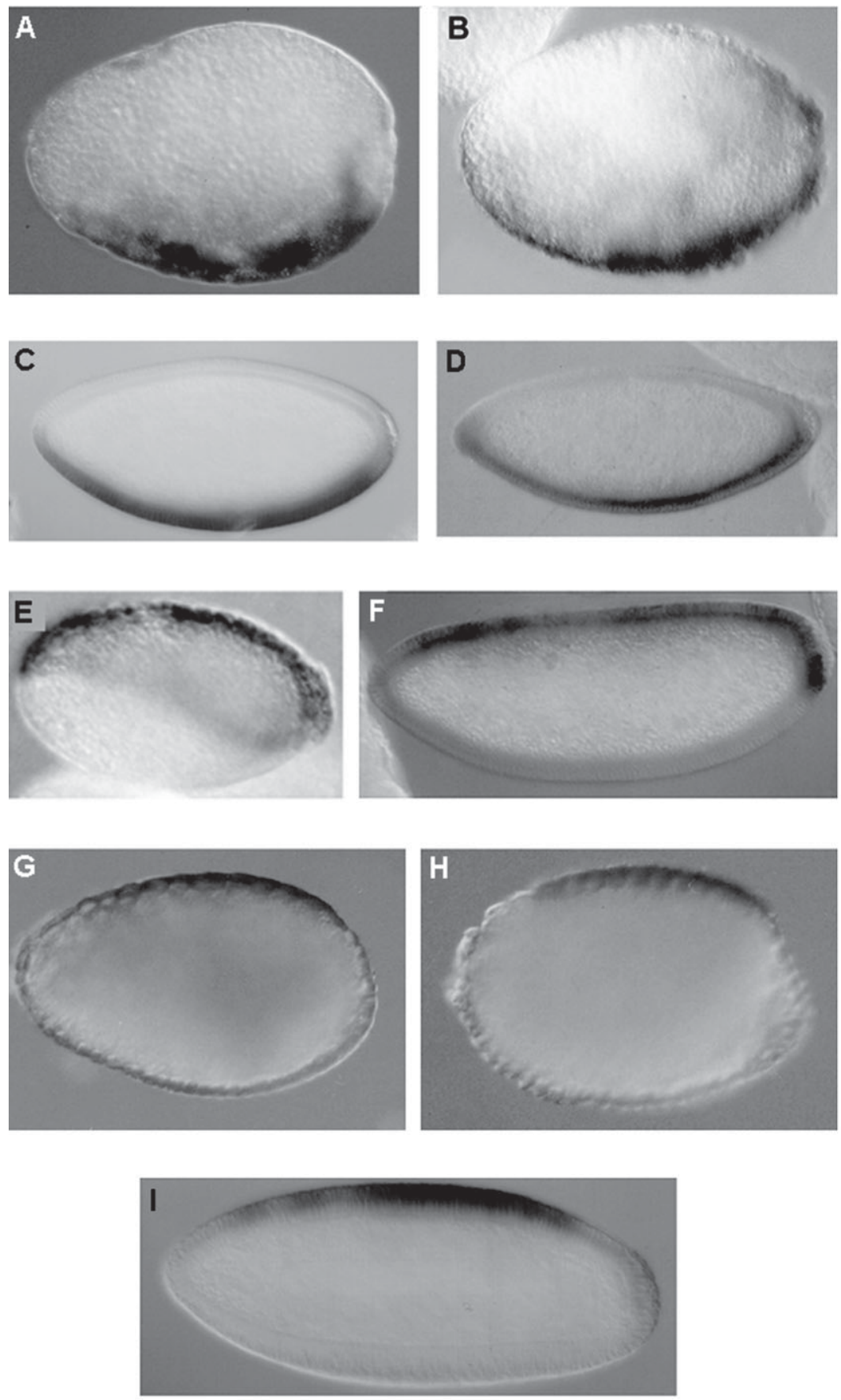

Figure 2. Analysis of dorsal-ventral gene expression in a Rhynchosciara americana embryo by whole-mount in situ hybridization. Anterior is to the left. $A-B$, sna and twi mRNA distribution in the syncytial blastoderm $(8 \mathrm{~h})$ and cellularization of nuclear blastoderm (12-18 h) stages, respectively. $C-D$, sna and twi expression in a Drosophila melanogaster embryo during the cellular blastoderm stage. $E-F$, dpp mRNA distribution in mid-cellular blastoderm stages of $R$. americana and $D$. melanogaster embryos, respectively. $G-H$, zen mRNA distribution during the early cellular blastoderm (24 h) and late cellular blastoderm stage (48 h) of an $R$. americana embryo, respectively. I, zen expression in a D. melanogaster embryo during the late cellular blastoderm stage. 
cies that reflects a modification in the way these genes are regulated. Nevertheless, we can say that the expression of the sna and twi genes is spatially and temporally conserved because both initiate their expression on the ventral surface and still in the precellular blastoderm stage, as they are in Drosophila.

The early expression of the dorsalizing genes $d p p$ and zen is not detected until cellular blastoderm stage of $R$. americana development. In contrast, in Drosophila both genes are initially expressed at the precellular blastoderm stage prior to nuclear cycle 14 . However, similar to Drosophila, in R. americana, the $d p p$ and zen domain of expression was localized in a dorsal region of the embryonary blastoderm (Figure 2E and G-H). During the cellular blastoderm stage the distribution of dpp mRNA and zen transcripts extends into the anteroposterior region of the embryo. In early stages $d p p$ transcripts always occupy a broader domain of expression than zen mRNA. Surprisingly, while in Drosophila $d p p$ expression is restricted to the dorsal non-neurogenic ectoderm region, in $R$. americana dpp expression seems to expand over the lateral ectoderm. Probably this expansion will be later reduced when the cells from the ventral region will migrate to the dorsal side of the embryo (11).

In Drosophila, dpp and zen are expressed in a region of the same extension. In later stages the zen pattern is refined, occupying a more dorsal and restricted area (6). This refinement seems not to occur in $R$. americana, reflecting fine modifications in the control of regulation that has been attained by evolutionary adaptation of the embryogenesis mode of $R$. americana. Previous study by Stauber et al. (13) in non-cyclorraphan flies has suggested that zen has other functions than dorsal-ventral patterning. zen has been proposed to substitute the bicoid morphogen in anteroposterior patterning. This seems not to be the case in R. americana since our results did not show any early zen expression. Taken together, the present data indicate that in general the early expression patterns of dorsal-ventral genes are conserved in $R$. americana.

\section{Acknowledgments}

We thank Terezinha Maria Castro-Silva for technical assistance. We are grateful to Dr. Stephen Small (New York University, USA) for providing the cDNAs.

\section{References}

1. Steward R, Zusman SB, Juang LH \& Schedl P (1988). The dorsal protein is distributed in a gradient in the early Drosophila embryos. Cell, 55: 487-495.

2. Jiang J, Rushlow CA, Zhou Q, Small S \& Levine M (1992). Individual dorsal morphogen binding sites mediate activation and repression in the Drosophila embryo. EMBO Journal, 11: 3147-3154.

3. Rushlow C, Frasch M, Doyle H \& Levine M (1987). Maternal regulation of zerknüllt: a homeobox gene controlling differentiation of dorsal tissues in Drosophila. Nature, 330: 583-586.

4. Thisse B, Stoetzel C, Messal M \& Perrin-Schmitt F (1987). Genes of the Drosophila maternal dorsal group control the specific expression of the zygotic gene twist in presumptive mesodermal cells. Genes and Development, 1: 709-715.

5. Roth S, Stein D \& Nüsslein-Volhard C (1989). A gradient of nuclear localization of the dorsal protein determines dorso-ventral pattern in Drosophila embryo. Cell, 59: 1189-1202.

6. Ray RP, Arora K, Nüsslein-Volhard C \& Gelbart WM (1991). The control of cell fate along dorso-ventral axis of the Drosophila em- bryo. Development, 113: 35-54.

7. Ferguson EL (1996). Conservation of dorso-ventral patterning in arthropods and chordates. Current Opinion in Genetics and Development, 6: 424-431.

8. Patel NH (1994). Development evolution: insights from studies of insect segmentation. Science, 266: 581-590.

9. Sommer RJ \& Tautz D (1994). Expression patterns of twist and snail in Tribolium (Coleoptera) suggest a homologous formation of mesoderm in long and short germ band insects. Developmental Genetics, 15: 32-37.

10. Dearden P, Grbic M, Falciani F \& Akam M (2000). Maternal expression and early zygotic regulation of the Hox 3/zen gene in the grasshopper Schistocerca gregaria. Evolution and Development, 2: 261-270.

11. Carvalho JC, Vanario-Alonso CE, Castro-Silva TM \& Abdelhay $E$ (1999). Specialized features of Rhynchosciara americana embryogenesis. International Journal of Insect Morphology and Embryology, 28: 309-319. 
12. Tautz D \& Pfeifle C (1989). A non-radioactive in situ hybridization method for the localization of specific RNAs in Drosophila embryos reveals translation control of the segmentation gene hunchback. Chromosoma, 98: 81-85.

13. Stauber M, Prell A \& Schimidt-Ott U (2002). A single Hox 3 gene with composite bicoid and zerknull characteristics in non-Cyclorra- phan flies. Proceedings of the National Academy of Sciences, USA, 99: 274-279.

14. Rohr KB, Tautz D \& Sander K (1999). Segmentation gene expression in the mothmidge Clogmia albipunctata (Diptera, Psychodidae) and other primitive dipterans. Development, Genes and Evolution, 209: $145-154$. 